\title{
La medición del impacto económico del turismo: Metodología y principales resultados de la Cuenta Satélite del Turismo en la Unión Europea
}

\section{Measuring the economic impact of tourism: Methodology and main results of the Tourism Satellite Account in the European Union}

Hugo Padrón Ávila iD, Universidad de La Laguna, España hpadrona@ull.edu.es

\section{RESUMEN}

Es necesario medir los impactos generados por el turismo para poder tomar decisiones que afecten a esta actividad. Una de las principales herramientas de medición de la misma es la Cuenta Satélite del Turismo (CST) por su carácter internacional. En este trabajo se ha procedido a comparar un total de 27 países, pertenecientes o relacionados con la Unión Europea (UE), a través de sus CST. La finalidad del trabajo es lograr extraer conclusiones generales acerca de cómo se estructura la actividad turística en estos países para identificar las diferencias existentes entre los mismos. Además, se ha decidido emplear una serie de datos complementarios para poder elaborar varios tipos de indicadores que faciliten el análisis. Por último, en este trabajo se analizan los inconvenientes vinculados al uso de la CST como herramienta de comparación y se recomiendan mejoras para una mejor recogida de estadística turística.

Palabras clave: Cuenta Satélite del Turismo; Unión Europea; medición; estadística turística; impacto del turismo

\begin{abstract}
Measuring the impacts generated by tourism is important to improve the decision-making process affecting this activity. One of the main tools used to do so is the Tourism Satellite Account (TSA) due to its international nature. In this research, a total of 27 countries belonging or closely related to the European Union (EU) are compared through their TSA. The aim of this paper is to obtain general conclusions about how the tourism activity is structured in these states so as to identify differences between them. In addition, supplementary data has been used in order to develop different types of rates for facilitating the analysis. Finally, the study analyzes the disadvantages linked to the use of TSAs as a comparison tool and the future improvements that are required in order to obtain a better collection of tourism statistics.
\end{abstract}


Keywords: Tourism Satellite Account; European Union; measurement; tourism statistic; tourism impact

\section{INTRODUCCIÓN}

La Organización Mundial del Turismo (OMT) define el turismo como "las actividades que realizan las personas durante sus viajes y estancias en lugares distintos al de su entorno habitual, por un periodo de tiempo consecutivo inferior a un año, con fines de ocio, por negocios y otros motivos no relacionados con el ejercicio de una actividad no remunerada en el país visitado" (Naciones Unidas, 2010a). Estas actividades suponen para los practicantes de turismo un conjunto de gastos que revierten en los destinos en forma de ingresos y empleos, entre otros. Ello hace necesario que el análisis del turismo requiera de un marco conceptual claro, de información estadística y de herramientas analíticas (Hernández, 2006).

La importancia de poder medir cuantitativamente la actividad turística reside en poder conocer cómo está estructurada esta actividad económica en un país determinado para poder tomar las decisiones oportunas con respecto a la misma (Organización Mundial del Turismo, 2012). Además, la creación de un sistema estándar a nivel internacional para recoger la información ayuda a poder comparar cómo se desarrolla la actividad turística en diferentes países (Frechtling, 1999). Es por ello que se crea la CST y se publican en 2001 las recomendaciones que deben tenerse en cuenta para recoger los datos de la misma (Naciones Unidas, 2001), publicándose en 2010 una nueva versión de las mismas (Naciones Unidas, 2010b). La CST constituye una estructura contable articulada y coherente que permite analizar de forma completa la importancia económica del turismo en un país o región, tanto desde una perspectiva de demanda como de oferta (Hernández, 2006).

En la actualidad, más de 60 países han confeccionado una CST (Frechtling, 2013). Sin embargo, a pesar de que los datos son de acceso público y fácil en muchos casos, no siempre han sido empleados para comparar la actividad turística de diferentes estados. En el presente trabajo se analiza la información presentada por 27 países (Eurostat, 2013) para poder extraer conclusiones relativas a cómo se estructura la actividad turística en la UE. La relevancia de este aporte se centra en permitir conocer cuáles son los destinos que reciben un mayor número de turistas, qué países son los principales emisores de turismo, cómo se estructura el gasto turístico en los diferentes estados, etc. Además, la información de la CST se combinará con otro tipo de datos que no son de naturaleza económica.

El objetivo del trabajo se centra en la comparación de una serie de países de la UE a través de sus CST. Para ello, se comienzan enumerando los factores que conducen a la necesidad de crear la CST, la relevancia de esta herramienta en la actualidad y la estructura de la misma. Luego, se realiza el análisis de una serie de países que facilitaron los datos relativos a sus CST a Eurostat para la realización de un informe (Eurostat, 2013), combinando esta información con otros datos complementarios. Por último, se muestran las razones por las que la información presentada en una CST no es del todo completa y los retos y cambios futuros a los que se enfrenta la elaboración de la misma. 


\section{II. ¿QUÉ ES LA CUENTA SATÉLITE DEL TURISMO?}

La CST es una de las herramientas de análisis más importantes que han sido desarrolladas en las últimas décadas para medir la demanda turística y los efectos directos que genera la misma en la economía de un país (Eurostat, 2009). Además, a través de una serie de variables y herramientas es posible interpretar su contenido para determinar las mejores políticas a llevar a cabo con el fin de maximizar los efectos positivos que el turismo puede generar (Organización Mundial del Turismo, 2012). Dada su importancia, la UE fomenta su realización para que los Estados Miembros puedan conocer cómo influye el turismo en sus economías y se puedan comparar estos países entre sí (Eurostat, 2013).

La CST es empleada en más de 60 países para medir los efectos directos del consumo turístico en sus economías nacionales (Frechtling, 2013). Formalmente, la CST comprende un conjunto de tablas, relacionadas entre sí, que muestran el tamaño y la distribución de las diferentes formas de consumo turístico en un país. Además, se señalan las contribuciones directas al Producto Interior Bruto (PIB), el valor añadido a nivel nacional, los ingresos por turismo, el empleo en la actividad y otras medidas macroeconómicas que afectan a una economía (Frechtling, 2013). Actualmente, la CST se realiza a nivel nacional y se centra en años naturales, aunque muestra ciertas estimaciones trimestrales (Frechtling, 2010). Sin embargo, comienza a demandarse la realización de CST a nivel regional para poder conocer en qué zonas se cobra más importancia el turismo y poder mejorar la gestión de la actividad en dichas zonas (Jones y Munday, 2010).

La CST se elabora a través de un manual aprobado por la División de Estadística de Naciones Unidas, la Comisión de las Comunidades Europeas, Eurostat, la OMT y la OCDE (Naciones Unidas, 2010a). La CST comprende una gran cantidad de información derivada del sistema de Cuentas Nacionales de un país y de su propio sistema de estadísticas en materia turística (Eurostat, 2002). Estos datos se analizan para tenerlos en cuenta a la hora de tomar decisiones tales como el gasto en promoción turística de un destino o la inversión en instalaciones para los visitantes e infraestructuras relacionadas con el turismo. Otros usos de los datos de una CST son: evaluar los efectos de las políticas públicas sobre la demanda y la oferta turística, medir el rendimiento de la inversión en el desarrollo del turismo y extraer conclusiones relativas a las características de los visitantes (Organización Mundial del Turismo, 2010).

Se debe aclarar que en una CST puede encontrarse información tanto desde el enfoque de oferta como desde el de demanda. Este último enfoque se divide, a su vez, en impactos directos e indirectos. Tradicionalmente, solo los directos eran tenidos en cuenta a la hora de elaborar una CST. Sin embargo, debido a que varios estados comienzan a presentar la información desde un enfoque de demanda indirecto, se decide elaborar un marco metodológico con recomendaciones sobre cómo recolectar este tipo de información. En la actualidad, en una CST pueden encontrarse ambos datos, que son presentados por separado para poder diferenciarlos. Ello se debe a que para ciertos países resulta imposible estimar los impactos indirectos y ello hace que sea necesario armonizar la información con el fin de poder usarla en análisis y comparaciones (Hernández, 2006). 
Uno de los objetivos principales de la CST, en su versión estándar, es obtener cinco principales agregados que proporcionan indicadores que miden el peso económico del turismo en un país. Estos agregados principales son: el gasto turístico interior, el consumo turístico interior, el Valor Añadido Bruto (VAB) de las empresas turísticas, el VAB directo del turismo y el PIB directo del turismo. El gasto turístico interior es el efectuado por los visitantes para adquirir bienes y servicios en el destino. El consumo turístico interior hace referencia al consumo en empresas características del turismo de los visitantes tanto residentes como no residentes. El VAB de las empresas turísticas es el resultado de sumar el VAB del total de empresas que realizan actividades características del turismo, independientemente de que vendan o no a turistas. El VAB directo del turismo es la parte del VAB generado por la venta de bienes y servicios a turistas por parte de las empresas turísticas y no turísticas del país. El PIB directo del turismo se halla sumando las partes del VAB generadas por todas las empresas como respuesta al consumo turístico interior, incluyéndose el pago de los impuestos (Frechtling, 2013).

La CST, en su versión estándar, está formada por 10 tablas diferentes. Cada una de ellas recoge una serie de datos relacionados entre sí y, en conjunto, contienen los cinco agregados principales mencionados. La primera tabla contiene datos relativos al consumo turístico de los turistas extranjeros por productos y categorías de visitantes. En la segunda tabla se presenta información del consumo turístico interno, también dividido por productos y tipología del visitante. En la tercera tabla pueden encontrarse datos del consumo turístico realizado por los residentes del país analizado en el extranjero, separados por productos y categorización de los turistas. En la cuarta tabla de la CST se muestra el consumo turístico interior por productos y tipos de turismo. La quinta tabla aporta datos de las cuentas de producción de las industrias turísticas y otras industrias. En la sexta tabla se pueden encontrar datos relativos al VAB del turismo y el PIB turístico. La información concerniente al empleo en las industrias turísticas se encuentra en la séptima tabla. En la octava se aportan datos de la formación bruta de capital fijo del turismo. En la novena se presenta el consumo colectivo del turismo. Por último, la décima tabla es la que contiene indicadores no monetarios, tales como número de viajes por tipos de turistas, número de llegadas por medios de transporte o número de establecimientos y su capacidad (Eurostat, 2009).

En la CST, el turismo receptor hace referencia a los visitantes extranjeros que deciden viajar a un país ajeno al propio. El turismo interior de un estado es el resultante de sumar el turismo interno y el receptor, es decir, el total de visitantes que recibe el mismo, ya sean residentes del país o extranjeros. Al desglosar el gasto turístico, en las CST existe un apartado calificado como Otros componentes del gasto, en el que cada país, atendiendo a la metodología empleada para elaborar sus CST, considera como tales una serie de gastos $u$ otros e incluso no considera ningún gasto en esta categoría. En el caso de España, por ejemplo, son considerados como Otros componentes del gasto los gastos relativos a Consumo colectivo del turismo y la formación bruta de capital fijo (inversión realizada en el país para crear las infraestructuras necesarias para desarrollar actividades turísticas). 


\section{OBJETIVOS}

En este trabajo se analizan las CST que se elaboran a nivel europeo para poder, con ello, extraer una visión general de cómo se estructura la actividad turística dentro de la UE. Para ello se deberán extraer y procesar los datos recogidos con el fin de poder fundamentar conclusiones acerca de en qué zonas se centra la actividad turística o qué países son los principales emisores de turistas. Además, se intentarán crear relaciones, a través de los datos disponibles, para conocer si ciertas variables están vinculadas y saber, por ejemplo, si es en los países más visitados donde se produce un mayor gasto turístico, si las principales naciones emisoras de turistas son de las que provienen los turistas más dispuestos a gastar en los destinos, etc.

La información necesaria para poder alcanzar estos objetivos se encuentra, sobre todo, en Tourism Satellite Accounts (TSAs) in Europe, siendo el documento del que se han extraído los datos para elaborar el informe (Eurostat, 2013). La información que muestra el mismo hace referencia a 2013, siendo el último recopilatorio de datos turísticos desarrollado por Eurostat hasta la fecha.

Por ello, el objetivo principal del trabajo consistirá en el análisis de ciertos indicadores de la CST, que fueron presentados por 22 países: 17 de ellos son Estados Miembros de la UE (Alemania, Eslovaquia, Eslovenia, España, Estonia, Francia, Italia, Letonia, Lituania, Países Bajos, Portugal, Reino Unido, República Checa, Rumanía y Suecia), 3 son países pertenecientes a la Asociación Europea de Libre Comercio (AELC) (Islandia, Noruega y Suiza) y 2 países candidatos a entrar en la UE (Montenegro y Turquía). La información principal se centra, según señala el propio informe, en los 17 Estados Miembros al representar cerca del $90 \%$ de la actividad turística de Europa, siendo, por lo tanto, representativos de la UE en su conjunto.

Un último objetivo consistirá en comprobar los límites que posee la CST, con la finalidad de dejar constancia de ellos y proponer mejoras. Por ello, se analizará la problemática que rodea a estos datos debido a diferencias en el método de recogida de los mismos entre distintos países, ausencia de ciertos tipos de datos necesarios para realizar una investigación más profunda, etc. Además, se intentarán proponer posibles mejoras que ayudarían a solventar dichos fallos y servirían para facilitar y fomentar los análisis y comparaciones internacionales en el futuro. Finalmente, se tratarán los retos actuales que enfrentan las CST, como la realización de un marco metodológico que explique cómo realizar CST a nivel regional o la contemplación de los impactos indirectos en las mismas.

\section{METODOLOGÍA}

Para lograr cumplir los objetivos propuestos, se ha decidido emplear las estadísticas turísticas recogidas en la CST, al tratarse de la base de datos turísticos comúnmente empleada para realizar comparaciones turísticas a nivel internacional y al estar impulsada su implementación por parte de la UE. Como se ha señalado, la estructura de la CST se divide en diez tablas. En cada una de ellas aparece información referente a cada uno de los países analizados, en forma de valores absolutos y relativos. 
A continuación, se procede a analizar algunos de los países pertenecientes a la UE, o vinculados con la misma, que aportaron a Eurostat la información relativa a sus CST. Estos datos sirvieron para que el informe Tourism Satellite Accounts in Europe pudiera realizarse en 2013 con el objetivo de poder extraer una visión global de la situación turística de Europa y ser capaces de comparar la importancia que posee la actividad turística en los países del continente (Eurostat, 2013).

En primer lugar, debe señalarse que el año de referencia en el que se basan los datos aportados varía según el país, pues el mismo depende de en qué año se hubiese realizado la CST aportada por cada nación para poder elaborar el informe mencionado. Así, nos encontramos con que los datos referentes a Francia y Letonia son de 2005; los de Portugal y Noruega de 2007; los de Estonia, España, Polonia y Suiza son de 2008; los de los Países Bajos, Rumanía, Eslovenia, Reino Unido y Montenegro son de 2009; los de Alemania, Italia, Lituania, Eslovaquia, Suecia, Islandia y Turquía son de 2010; y los de República Checa y Austria son de 2011 (Eurostat, 2013). Los gráficos y datos aportados en el artículo derivan, por tanto, de anualidades diferentes para cada país. A pesar de que no se trata de la condición idónea para realizar una comparativa coyuntural turística, la realización de una CST requiere de un enorme esfuerzo, tanto económico como temporal, por parte de los países que la realizan. Por ello, muchos países la han realizado únicamente en una ocasión y, otros países, la realizan cada cierto tiempo (normalmente una vez cada 10 o más años). Por ello, no existen datos de un único año que permitan realizar una comparación más adecuada.

Además, cabe destacar que la institución encargada de recoger los datos para la elaboración de la CST cambia según el país, pues la misma varía atendiendo a la legislación estatal. Así, en la mayor parte de los países, es el instituto nacional de estadística el que lleva a cabo esta tarea. Sin embargo, en Alemania y Polonia es el ministerio responsable de la actividad turística el encargado de cumplir con esta labor. En el caso de Francia, la tarea recae en la Dirección General de Competitividad, Industria y Servicios y en el Banco de Francia. En Suecia el encargado de esta labor es el Riskbanken (Eurostat, 2013). Esta diversidad de organismos puede explicar por qué varían los datos recopilados en función del país que los recoge, ya que, al tratarse de distintos organismos, los intereses de cada uno de ellos son diferentes. Además, esto explica también por qué ciertos datos son únicamente recopilados por ciertos países. También explica otros factores como por qué algunos países diferencian entre trabajadores a jornada completa y trabajadores a jornada parcial (otros ignoran esta diferenciación) o por qué muchos países no han considerado ningún tipo de gasto como "otros componentes del consumo turístico".

Como al utilizar los datos aportados por el informe se ha visto que los países de mayor dimensión son los que presentan mayores valores absolutos en las macromagnitudes turísticas, se ha decidido consultar también fuentes externas al informe para poder ofrecer información relativa, en forma de tasas. Ejemplos de la información buscada son la superficie de los países o el número de habitantes. Los cuadros con los datos extraídos del estudio de las CST europeas se encuentran en el Anexo del trabajo. Sin embargo, en el desarrollo de los resultados se ofrecen una serie de gráficos con datos de los casos de estudio más relevantes. 


\section{RESULTADOS DEL ANÁLISIS DE LAS CUENTAS SATÉLITE DEL TURISMO DE LA UNIÓN EUROPEA}

En el Gráfico 1, se muestra información acerca de la propensión bruta turística (número medio de viajes realizado por ciudadano en cada país), lo que es de ayuda para saber qué nacionalidades son más propensas a viajar (ya sea dentro o fuera del estado). Para hallarlo se ha dividido el número total de viajes realizados entre la población total de cada país (datos de 2010). De este modo, cabe destacar que los países en los que la población posee una actitud más positiva hacia la realización de viajes turísticos son Finlandia, Dinamarca, Suecia y Noruega. Es preciso resaltar que Alemania, Francia, España y Reino Unido son los mayores emisores de turistas, mostrando los valores agregados más elevados; pero sus habitantes no realizan tantos viajes por persona como los países antes mencionados. Por otro lado, son los habitantes de Rumanía, Bulgaria, Grecia y Polonia los que se muestran menos propensos a viajar.

Gráfico 1. Propensión bruta turística

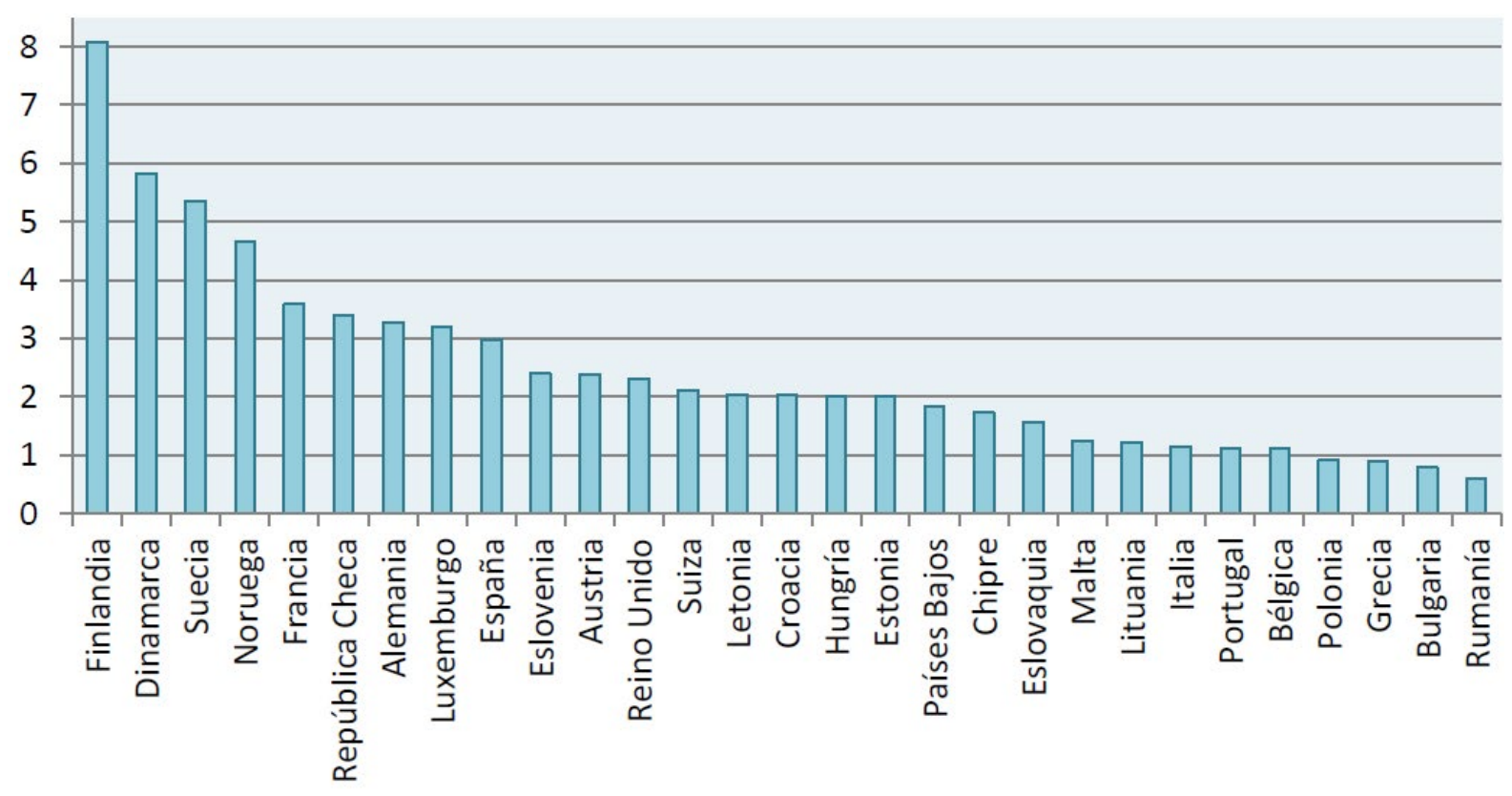

Fuente: elaboración propia a partir de datos de Eurostat

La CST dispone de información acerca del gasto realizado por los turistas extranjeros en cada uno de los países analizados. España, Francia, Alemania, Italia y Reino Unido son los países en los que los visitantes realizan un mayor gasto total. Este aspecto se ve influenciado, en parte, porque en estos países se produce un mayor gasto medio por turista que en otros Estados Miembros de la UE. Sin embargo, no es la única razón, ya que en Noruega e Islandia el gasto por turista es mayor. La explicación para esto sería que en los países antes nombrados (España, Francia, Alemania, Italia y Reino Unido) se combinan una mayor entrada de turistas y un alto gasto medio por turista, originando el gran gasto turístico que reflejan estos países. También se debe considerar que, a pesar de que es en Noruega e Islandia donde se produce 
un mayor gasto por turista, el gasto por noche de estancia es bajo en comparación con otros países analizados. Esto indica que el enorme gasto por turista que se origina en estos países no se debe al precio de los alojamientos, sino al gasto realizado por los turistas en otras actividades turísticas (transporte, restauración, actividades de ocio, complementarias, etc.) o, especialmente, a que permanecen en el destino durante períodos más largos.

Resulta de interés el caso de Eslovenia, que es el único país donde se produce un mayor gasto por parte de los excursionistas extranjeros que el originado por los turistas que se alojan en el país al menos una noche, seguramente porque también son más los turistas que visitan el país en un día que los que pernoctan en él (podría deberse a que posee la segunda mayor tarifa de gasto medio por noche de estancia, desincentivando a los viajeros a pernoctar). A continuación, se presenta un gráfico para poner de manifiesto esta información de manera más clara, se han eliminado del mismo a los países que no diferenciaban a sus visitantes entre turistas y excursionistas y a los que los consideraban a todos como turistas.

Gráfico 2. Distribución del gasto entre turistas y excursionistas extranjeros

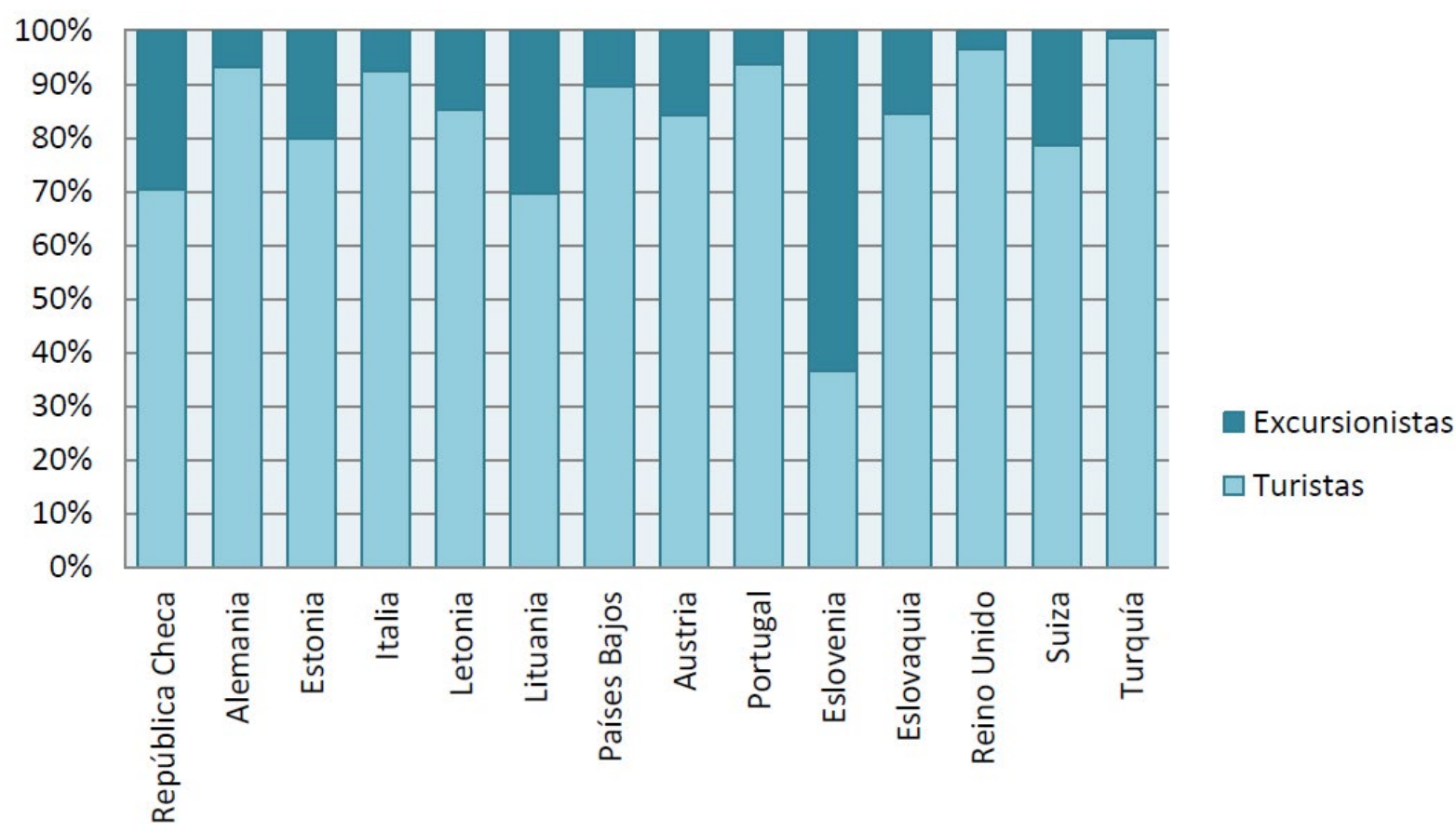

Fuente: elaboración propia a partir de datos de Eurostat

La CST también dispone de información relativa al gasto por turismo interno (turistas que viajan dentro de su propio país). Resulta interesante comprobar cómo existen algunos países en los que es mayor el gasto anual ocasionado por los visitantes que no pernoctan que el gasto total anual generado por aquellos visitantes nacionales que deciden viajar dentro de su propio país y se alojan en el destino visitado. Casos en los que ocurre este hecho son los de Alemania, Letonia, Países Bajos y Reino Unido. En Reino Unido la diferencia entre el gasto agregado de los excursionistas y los turistas que pernoctan es bastante pequeña. En el caso de Letonia se produce un $68 \%$ más de gasto por parte de los excursionistas. En el de Alemania la 
diferencia porcentual entre el gasto por parte de los turistas y el de los excursionistas es similar a la de Letonia. Sin embargo, la diferencia en valores absolutos es mayor y más fácilmente apreciable, al contar con unos valores de gasto agregado mucho mayores que los presentados en el caso de Letonia. Por último, el ejemplo más sobresaliente es el de los Países Bajos, donde el gasto agregado de los visitantes de un solo día es mayor que el doble del gasto de los que pernoctan en el destino. Para el resto de países, la diferencia entre estos gastos tiende a ser mucho mayor y a concentrarse en el gasto realizado por los turistas que pernoctan. Se presenta a continuación un gráfico similar al anterior, pero con el valor porcentual que representa en cada estado el gasto agregado por parte de excursionistas y turistas internos.

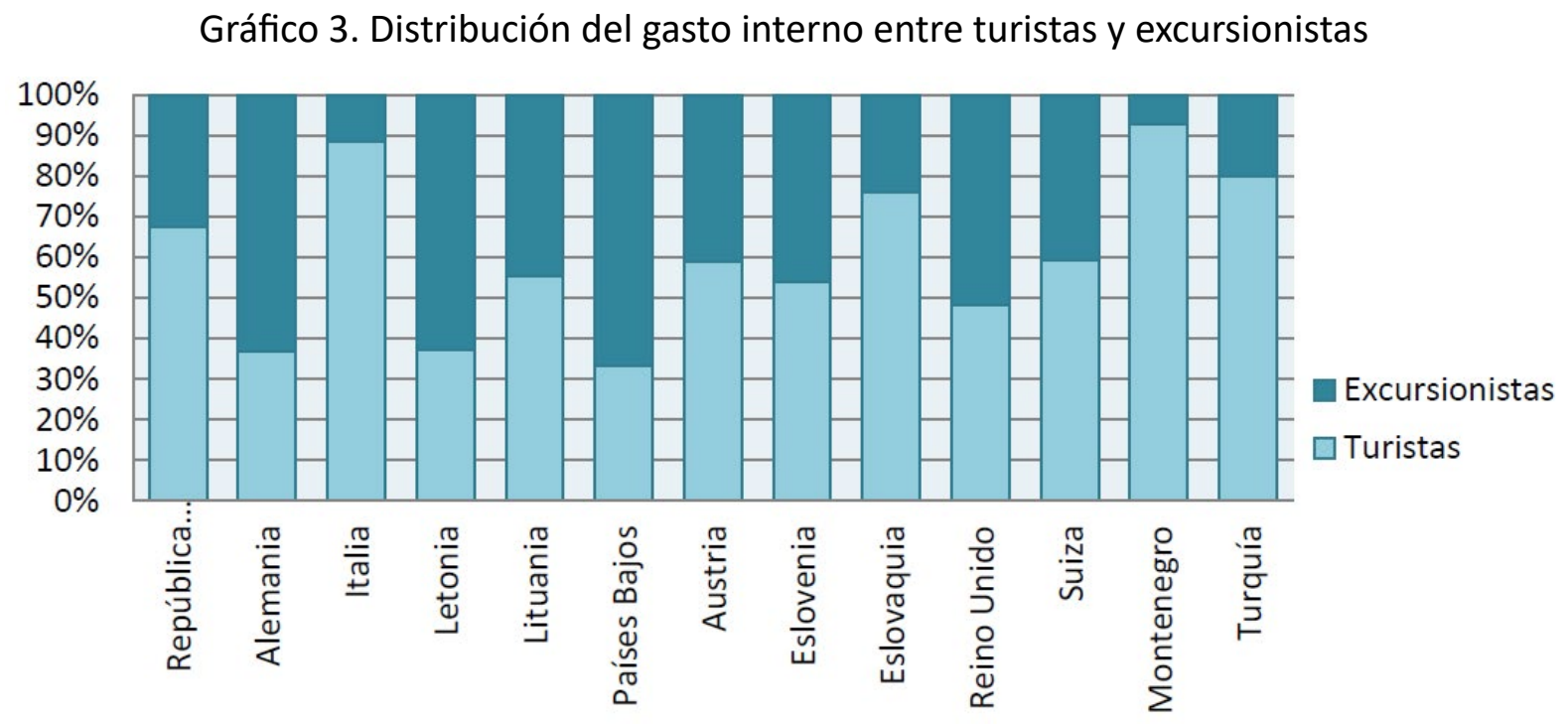

Fuente: elaboración propia a partir de datos de Eurostat

La CST dispone también de datos sobre el consumo en actividades turísticas incurrido dentro de cada país. El mismo está formado por el gasto en turismo dentro del país, sumando también otros componentes del gasto que se hayan decidido contemplar. Los gastos considerados como "otros componentes del consumo turístico" varían en función de cada país y del organismo encargado de recopilar los datos. Por ello, en algunos casos pueden referirse a tasas e impuestos, subvenciones de la administración pública para reducir el precio de ciertos servicios, etc. La base de datos consultada no contenía información detallando qué había considerado cada país dentro de esta categoría. A su vez, el gasto en turismo dentro del país se presenta desglosado entre el gasto generado por los turistas extranjeros y el generado por los turistas domésticos. En los países que no tienen en cuenta otros componentes del consumo, el consumo turístico interior es igual al gasto turístico, es decir a la suma del gasto de turistas extranjeros y domésticos. Se expone a continuación un gráfico en el que se muestra qué parte del consumo turístico interior total de cada país se corresponde a cada uno de los elementos que lo componen. 
Gráfico 4. Valor relativo de los componentes del consumo turístico interior

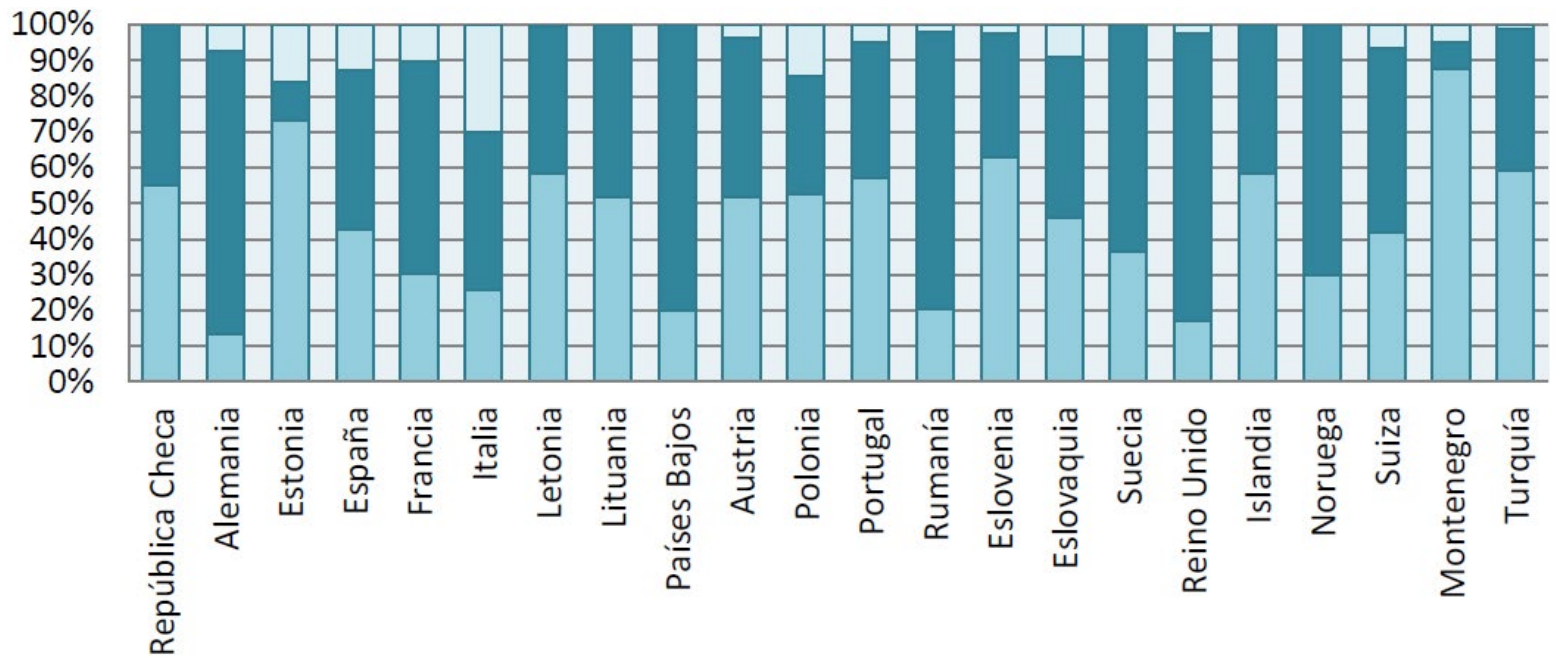

$\square$ Gasto del turista extranjero

Gasto del turista interno

Otros componentes del consumo turístico

Fuente: elaboración propia a partir de datos de Eurostat

Resulta de interés, el hecho de que haya países en los que el gasto originado por los turistas domésticos sea mayor que el generado por los extranjeros. Tal es el caso de Alemania, España, Francia, Países Bajos, Rumanía, Suecia, Reino Unido, Noruega y Suiza. Ello indica que son muchos los turistas que prefieren no salir del país en el que residen y gastan en actividades turísticas dentro del mismo. Son varias las razones que podrían explicar este hecho. Por ejemplo, ello podría deberse a que los turistas prefieren no traspasar las fronteras de la nación con el objetivo de ahorrar en el viaje al no tener que pagar tanto por el transporte y ello motiva la existencia de un alto número de personas que viajan dentro de los límites nacionales. Otro motivo podría ser el no necesitar cambiar de moneda para viajar (casos de Reino Unido, Noruega y Suiza) y abaratar con ello el coste total del viaje.

La CST también permite conocer cuánto han gastado los residentes de un país al viajar al extranjero. Alemania, España, Francia, Italia y Reino Unido vuelven a destacar en valores absolutos. En este caso nos encontramos con que no solo son grandes receptores de turismo, sino que también son las naciones que emiten los turistas más dispuestos a pagar por turismo en el extranjero, teniendo las tasas de gasto por viaje más elevadas. También destacan estos países, junto con Países Bajos, por ser los que emiten los turistas más dispuestos a gastar por noche de estancia fuera de las fronteras nacionales. De entre todos esos países, se debe hacer especial mención al caso de España al ser sus ciudadanos los que más gastan por viaje realizado, con bastante diferencia con respecto al resto de estados analizados. Ello puede ser debido, en gran medida, a que es también desde donde salen los turistas más dispuestos a gastar por noche de estancia, lo que multiplica significativamente el coste del viaje por día, y explica que sea también desde aquí desde donde parten los turistas que gastan más por viaje al pernoctar en el extranjero. 
Es también relevante el caso de Países Bajos, pues es un país que destaca enormemente por la generación de turistas dispuestos tanto a viajar dentro del propio país como hacia el extranjero. Además, resulta ser también uno de los países que emite los turistas que producen un mayor consumo en actividades turísticas, teniendo una de las mayores tasas de gasto medio por turista y viaje. Esto se ve fomentado por el hecho de poseer la tercera mayor tasa de gasto por noche de estancia por parte de sus residentes en el extranjero. Lo que diferencia Países Bajos de otras naciones importantes en cuanto a la generación de turistas (Alemania, Francia, España, Reino Unido) es el no ser un importante receptor de turismo. De hecho, sus valores se encuentran próximos a la media de los países estudiados y no destaca por ser receptor de turistas ni porque se genere un gran gasto por parte de los mismos. Véase el Gráfico 5.

Gráfico 5. Diferentes tipos de gasto turístico en seis países europeos

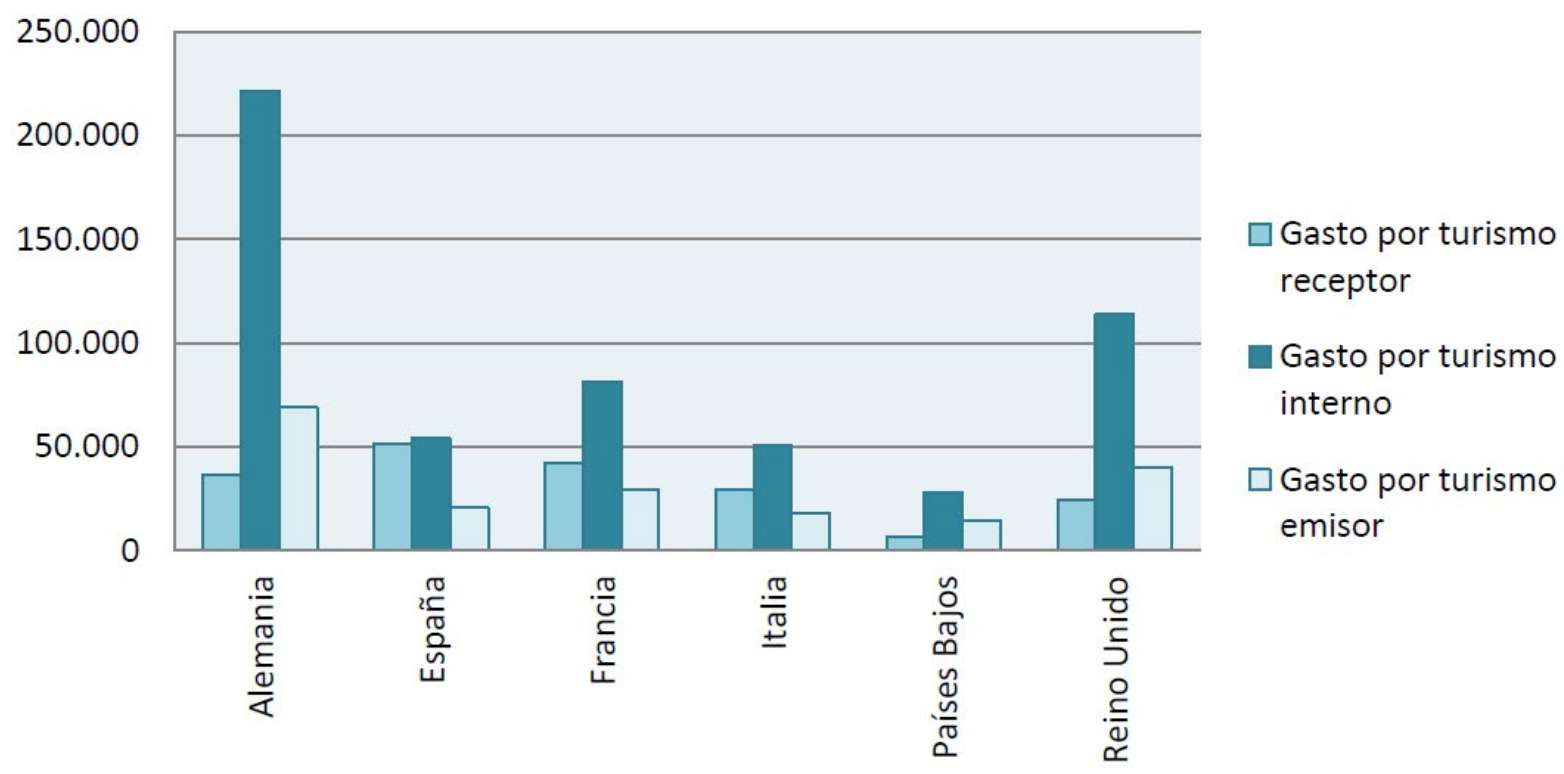

Fuente: elaboración propia a partir de datos de Eurostat

La CST muestra información relativa al empleo generado en las empresas turísticas de cada uno de los países estudiados. Los datos transmitidos han sido: número de puestos totales creados en actividades turísticas en cada país, horas trabajadas por parte de los empleados en cada país y número de puestos a jornada completa. Se han excluido los casos de Estonia, Francia, Italia, Rumanía, Eslovenia y Turquía debido a que no han recogido ninguno de los datos requeridos para realizar la misma. Los países en los que las empresas turísticas han creado una mayor cantidad de puestos de trabajo han sido Reino Unido, Alemania y España. Es lógico entender que estos países presenten estos datos al ser los más grandes y los que cuentan con un mayor número de habitantes. Sin embargo, sí que resulta interesante fijarse en el porcentaje de población total empleada en actividades turísticas. Esto ayuda a comprobar qué importancia posee el turismo en la generación de empleo de los estados estudiados. También es interesante fijarse en la cantidad relativa de empleos a jornada completa. Llama la atención el hecho de que en Reino Unido solo sean a tiempo completo, aproximadamente, 
el $75 \%$ de los puestos en empresas turísticas. Por su parte, en España lo son cerca del $87 \%$ de los empleos creados en actividades turísticas. Así, podemos observar que Islandia, República Checa, Eslovaquia y Portugal son los países donde más puestos a jornada completa son ofrecidos en comparación con la totalidad de puestos de trabajo en actividades turísticas. Además, se observa que la nación en la que existe un menor número de puestos a tiempo completo en la actividad, con relación al total de puestos generados, es Países Bajos (62\%).

En el Gráfico 6 se observa el porcentaje de población total empleada en turismo y se diferencia a los empleados a jornada completa de los empleados a tiempo parcial (solo en caso de que cedieran este dato). Algunos países solo habían cedidos datos relativos al número de empleos totales en actividades turísticas, considerando todos ellos como empleos a jornada completa. No han especificado si realmente todos estos empleos son a jornada completa o si se han considerado también los contratos a jornada parcial. Los países que no han realizado esta diferenciación son: Letonia, Alemania, Noruega, Islandia, Suiza, Suecia, Lituania, Montenegro y Polonia. A pesar de ello, se han incluido en el gráfico, al permitir observar qué porcentaje de la población trabaja en turismo.

Gráfico 6. Porcentaje de población total empleada en turismo

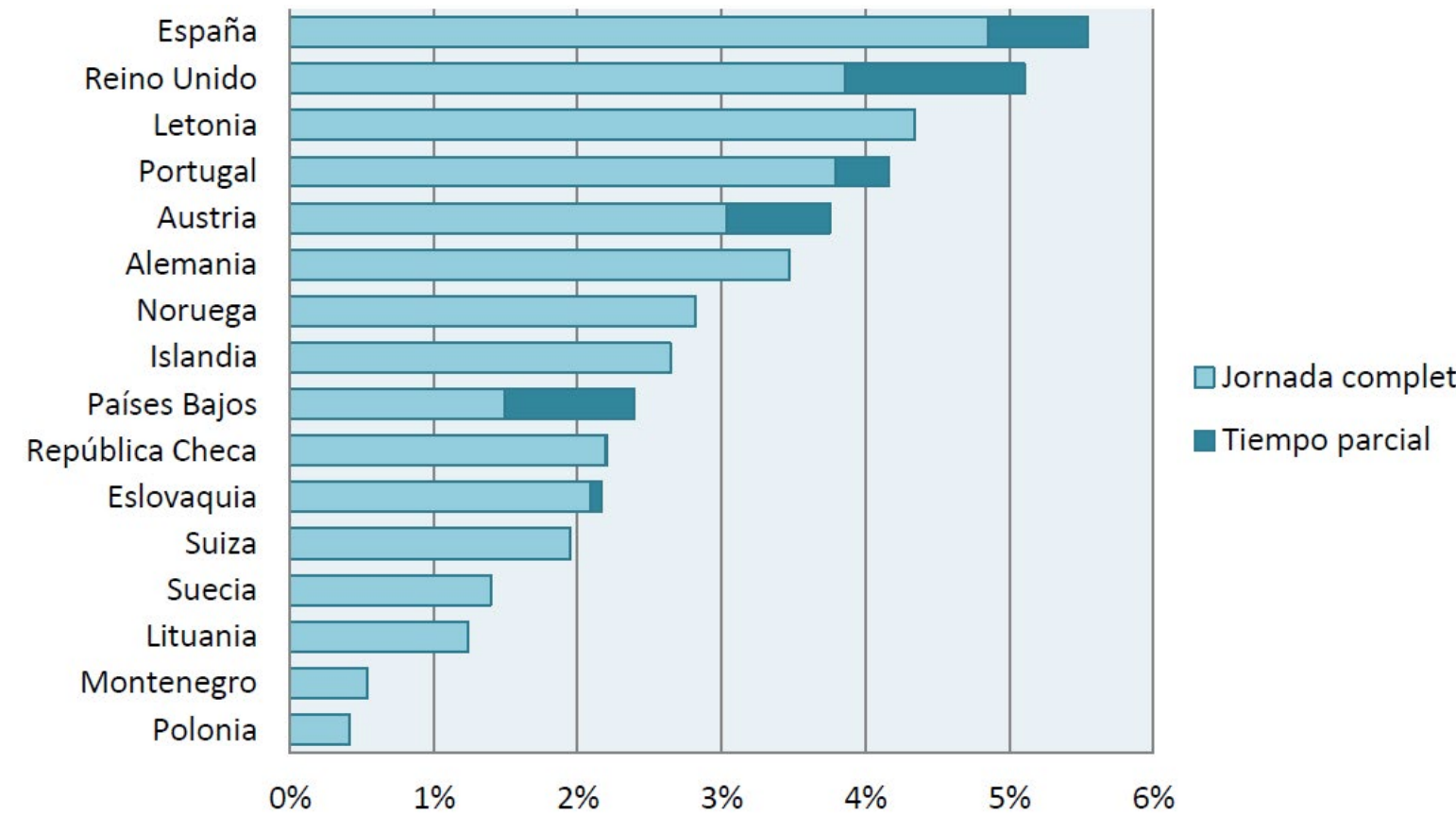

Fuente: elaboración propia a partir de datos de Eurostat

La CST también contienen datos no monetarios, como el número de turistas recibidos por un país. España y en Francia son los destinos que reciben un mayor número de turistas internacionales. Francia atrae, con una diferencia notable, un mayor número de turistas extranjeros. Sin embargo, la mayoría de los mismos solo se alojan durante un día en el país. Esto explica que, en pernoctaciones realizadas por los turistas que han visitado cada país, el dato para el estado francés se encuentre muy próximo al del español. Estos países, junto con 
Alemania, destacan también en cuanto a número de turistas internos. Llama la atención que en ambos casos (turismo receptor e interno) destaquen los viajeros que se alojan durante un único día en el conjunto de países analizados. Ello puede ser muestra de una tendencia por parte del turista actual a realizar estancias cortas en los destinos que visita, con ciertas excepciones como lo son el dato relativo a turismo interno para el caso francés. Se debe mencionar que los países de Europa Occidental atraen un mayor número de visitantes, pero la mayoría de los turistas que visitan estos destinos son residentes en el propio país. Sin embargo, en los países de Europa del Este, donde no existe una industria turística tan potente, son más los turistas provenientes del extranjero que los nacionales (salvo los casos de República Checa, Letonia y Lituania donde predomina, con diferencia, el turismo interno).

Gráfico 7. Representación del turismo receptor frente al interno

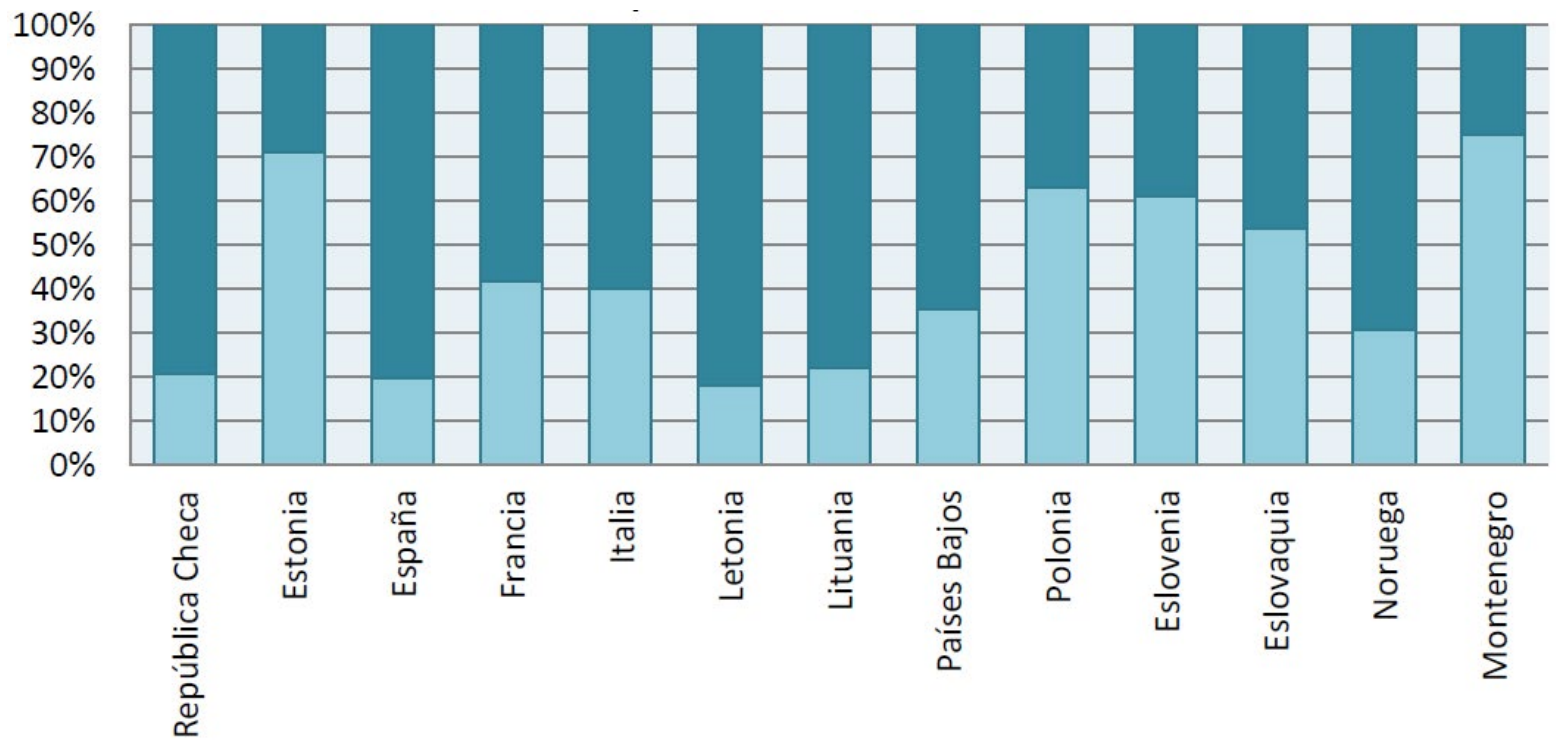

$\square$ Turismo receptor $\square$ Turismo interno

Fuente: elaboración propia a partir de datos de Eurostat

Los países que emiten un mayor número de turistas son Alemania, Polonia, Italia y Francia. No obstante, si se echa un vistazo al número de días de estancia por nacionalidades, vemos que son los alemanes, italianos, franceses, neerlandeses y españoles los que permanecen más tiempo en el extranjero. De esto se podría concluir que es en los países de Europa Occidental de donde proceden la mayor parte de turistas generados en el continente, debido a que son los que más viajan tanto dentro como fuera de sus países. La explicación de este hecho parece relacionarse con la mayor renta por habitante y, vinculado a ello, una mayor tradición de viajar.

\section{CRÍTICA Y PROBLEMÁTICA LIGADAS A LA CUENTA SATÉLITE DEL TURISMO}

A pesar de que la CST es la principal herramienta de análisis económico del turismo, se debe señalar que no se puede basar la toma de decisiones políticas en materia turística 
solamente en la misma. Como en muchos otros sistemas estadísticos y bases de datos, la economía es el eje central para el que se recaba la información. Ello implica que se terminen obviando otros ámbitos vinculados a los destinos turísticos como lo son la sociedad, la cultura y la naturaleza (Organización Mundial del Turismo, 2010). Estos componentes también están ligados a la actividad turística y se ven modificados por la misma. Sin embargo, no se mide cómo les afecta dicha actividad. La razón de ello es la dificultad que entraña medir este tipo de información, por su naturaleza cualitativa.

Otros datos reseñables que no se recogen en una CST son los referentes a otras variables que guardan relación con las económicas y que, al no tenerlos en cuenta, dificultan la comprensión de la economía de un país. Un ejemplo de ello puede apreciarse en los casos de países de dimensiones reducidas, como Liechtenstein o Luxemburgo, donde los turistas pasan un menor número de noches en establecimientos turísticos. Esto llevaría a pensar que la actividad no tiene gran relevancia en los mismos. Sin embargo, esta visión cambia si se compara esto con datos geográficos, como la dimensión de estos países. Así, dichos datos se explican debido a que son estados pequeños y no pueden, por ello, contar con gran cantidad de establecimientos dedicados a la actividad turística. Algo similar puede verse en el caso de Suiza, país donde más peso económico representa el turismo de los estudiados. También son necesarios datos acerca de la demografía de los países, como en el Gráfico 1, en el que se exponen las nacionalidades más propensas a viajar al dividir el número de viajes totales realizados por los habitantes de un país entre la población total.

Hay ciertas variables económicas más allá de los efectos directos que no son recogidas en una CST. Tal es el caso de los efectos indirectos y los inducidos, explicados anteriormente. Ello se debe a que la CST no fue diseñada para recoger efectos económicos secundarios, pues la estimación de los mismos requiere pasar de definir y rellenar tablas a diseñar e implementar modelos económicos (Frechtling, 2013). Esto significaría crear representaciones simplificadas de los elementos de una economía para identificar las principales variables y relaciones entre estos elementos y poder luego estimar ciertas variables macroeconómicas que no se podrían observar directamente. A pesar de ello, el no recoger datos relativos a estas variables impide un análisis completo de la actividad turística en estos países y hace imposible conocer la importancia económica real del turismo en los mismos. En la práctica, en el caso de España el INE sí estima los impactos indirectos del turismo, lo que requiere de un Modelo Input-Output y permite unos resultados más concluyentes y relevantes acerca de la contribución económica del turismo.

La cantidad de datos disponibles en las tablas varía mucho entre los países analizados. En el caso de Turquía solo se aportaron 18 indicadores y en el de Eslovaquia fueron 48. Hay que destacar que ningún estado cedió los 50 indicadores solicitados, lo que es muestra de que el turismo no es una prioridad en materia política. Los cuadros relativos a la demanda están relativamente completos, pero en la tabla del empleo disponemos de menos de la mitad de la información solicitada. Además, los datos acerca de la formación bruta de capital fijo y el consumo colectivo son escasos. Todo ello hace que sea difícil extraer conclusiones generales relativas a todos los estados estudiados, pues no disponer de todos sus datos imposibilita el llevar a cabo una comparación eficaz. Una posible acción futura debería centrarse en la 
ampliación de la cobertura de la CST mediante la inclusión de más países y la profundización en la información mediante la introducción de más tablas y variables.

La comparación de los indicadores se vio también afectada por la existencia de diferentes grados de adhesión a las recomendaciones para elaborar la CST, comunicadas en 2008 (Naciones Unidas, 2010b). Además, debido a la falta y, a la vez, variedad de fuentes, un número significativo de indicadores difería ligeramente de las recomendaciones o no estaban disponibles debido a la metodología llevada a cabo para recabar los datos (Eurostat, 2013). Un segundo factor que afecta a la comparación fueron los años de referencia utilizados, encontrando países que han aportado datos correspondientes a 2005 hasta otros que han cedido la información relativa a 2011. Sin embargo, dado que la CST es una herramienta de análisis estructural, todavía tenía sentido comparar los datos de los países participantes según el peso de cada variable. Aun así, cabe señalar que en este período temporal han acontecido hechos que han afectado significativamente a la actividad turística como lo son la crisis económica o la Primavera Árabe, poniendo en duda los resultados alcanzados. Es por ello, que se comienza a demandar que las CST cuenten con un apartado en el que se recojan ciertas previsiones de cómo evolucionará el sector, lo que podría facilitar la comparación de países que realicen sus CST en años diferentes.

Otra problemática relativa a la CST sobre la que debe hacerse mención es el hecho de que los datos que se publican en la misma hacen referencia a la totalidad del país que recopila la información. Lo cierto es que esto puede ayudar a los estados a conocer cómo influye el turismo en la totalidad de la economía nacional. Sin embargo, la actividad turística se centra en ciertos destinos del país y no suele darse por igual en todo el territorio nacional (Jones y Munday, 2010). La necesidad de saber dónde se centra en concreto la actividad turística para poder gestionarla con mayor precisión ha llevado a buscar alternativas a la CST tradicional. Es por ello que recientemente se ha creado INRouTe, dirigido por Antonio Massieu y apoyado por la Organización Mundial del Turismo, con el objetivo de fomentar las estadísticas turísticas a nivel regional. Para ello, se ha procedido a intentar armonizar la metodología de recogida de los datos y a crear unas bases para decidir cuándo considerar una región como turística. Esto serviría para saber dónde realizar la CST, pues las regiones sin actividad turística relevante no resultan tan interesantes. Además, estas regiones cuentan con empresas consideradas como turísticas (como bares y restaurantes), pero donde los que consumen no son los visitantes y, sin embargo, su consumo sería recogido como turístico. Hacer mención al hecho de que ya ha habido antecedentes de regiones que han elaborado una CST, de hecho ya se ha llegado a realizar en Canarias (Hernández Martín, 2011).

Por último, señalar la inexactitud de los datos presentados en una CST debido a que, tradicionalmente, no se han tenido en cuenta los impactos económicos indirectos que genera la actividad turística. Actualmente, existen recomendaciones elaboradas por la OMT relativas a la metodología que debe llevarse a cabo para recoger este tipo de efectos (Naciones Unidas, 2010b). Sin embargo, no todos los países pueden presentar esta información debido a que requiere el empleo del modelo de Leontief para poder realizar las estimaciones necesarias con las que poder calcular este tipo de datos (Hernández, 2006). 


\section{CONCLUSIONES}

Como se ha visto, la CST es una importante herramienta de análisis de la actividad turística a nivel nacional y puede emplearse para conocer cómo está estructurado el sector turístico en un país determinado. Además, sirve como método de comparación entre diversos estados para lograr extraer conclusiones generales acerca de cómo se estructura el turismo a nivel internacional. Se aprecia su importancia como herramienta de medición al observar la gran cantidad de indicadores necesarios para su elaboración y ver cómo los mismos han sido recogidos, debido a la relevancia de esta actividad económica.

Gracias a las CST estudiadas, puede comprobarse, a través del VAB turístico, el gran peso que posee el turismo en la UE y cómo contribuye esta actividad a la totalidad de la economía de los países. Además, también es interesante ver los numerosos puestos de trabajo que la misma genera y el gasto en el que incurren los visitantes extranjeros, que se transforma en beneficios para las empresas que atienden a los turistas en los destinos. Así, la CST ayuda a generar una visión de cómo el turismo fomenta el desarrollo y el crecimiento económico de los países y su influencia en la generación de empleo y la inversión para crear infraestructuras.

El análisis realizado ha permitido comprobar que los países en los que el turismo genera unos mayores ingresos, en valores absolutos, se localizan en Europa Occidental y la actividad se centra en Alemania, España, Francia, Italia y Reino Unido. Siendo estos estados los principales receptores de turistas del continente. En términos generales, son estos estados los que poseen una mayor dependencia económica del turismo, al ser en los que más representa la actividad en el total de su economía. Otros casos destacables son los de Suiza e Islandia, donde en términos absolutos el consumo turístico no es tan elevado, pero en términos relativos la actividad es un importante motor económico. El caso de Alemania es singular porque el peso económico que el turismo posee en el país está relacionado con el consumo turístico interno.

Además, el poseer unos niveles de producción turística mayores es, a su vez, la causa de que en los países mencionados se creen un mayor número de puestos de trabajo en dicha industria. El fomento de la creación de empleo podría ayudar a explicar el que sea en esos mismos países desde donde son emitidos más turistas, debido a la actitud positiva de sus habitantes hacia la actividad y el aumento de las rentas. Además, si analizamos el Gráfico 1, se aprecia que la población de estos estados presenta una mayor propensión bruta a viajar. Aun así, debe mencionarse que es en los países nórdicos donde más viajes por habitante se realizan y, sin embargo, la actividad turística en los mismos es reducida. Otro caso de interés es el de Países Bajos, donde la llegada de turistas extranjeros es reducida tanto en valores absolutos como relativos, pero desde donde se emite un gran número de turistas.

En Europa del Este, la actividad turística no posee tanta relevancia, no recibiendo tantos turistas como en el resto del continente, lo que conlleva que se produzca en estos países un menor consumo turístico. Además, la oferta total de bienes y servicios de estos países es mucho más reducida que el del resto de casos estudiados y la ratio turística también tiende a ser inferior a la de los casos ya analizados. Todo ello conlleva que no sean creados tantos puestos de trabajo en la actividad como en los otros estados mencionados y, además, son menos los turistas emitidos desde estos países al extranjero. De entre estos estados cabe 
destacar Estonia por poseer la ratio turística más elevada. Señalar que el consumo turístico que se produce en el país es bastante bajo, pero tiene cierta importancia económica al poseer una oferta total de bienes y servicios también es reducida, dando como resultado una ratio turística relativamente elevada. También son interesantes los casos de República Checa y Polonia por ser los principales receptores y emisores de turistas de Europa del Este en términos absolutos.

Resulta de sumo interés realizar una comparación entre el gasto producido por parte de turistas extranjeros uno de los países y el gasto llevado a cabo por los turistas emitidos por cada uno de ellos. La razón es que ello sirve para poder clasificar los estados por tener en la Balanza de Pagos un saldo positivo o negativo en materia turística. Así, podemos indicar que la existencia de flujos turísticos afecta positivamente a la Balanza de Pagos en República Checa, España, Francia, Italia, Letonia, Austria, Portugal, Eslovenia, Eslovaquia, Islandia, Suiza, Montenegro y Turquía. En estos países, los flujos turísticos les permiten recibir una mayor cantidad de divisas extranjeras en comparación con las gastadas por sus habitantes al viajar en el extranjero. Por otro lado, nos encontramos con que, en Alemania, Lituania, Países Bajos y Reino Unido es mayor el gasto realizado en el exterior que el originado dentro del país por parte de los turistas, afectando el turismo negativamente a su Balanza de Pagos.

Por último, comentar la problemática existente con la CST en cuanto a su importancia como herramienta de análisis del impacto de la actividad turística en la totalidad de la economía. Como ya se ha señalado, presenta ciertas carencias que impiden un análisis completo del turismo y ponen en cuestión la relevancia de los datos aportados. Además, al ser un sistema únicamente económico, no se pueden basar las decisiones políticas únicamente en los datos que presenta y debe complementarse con herramientas de medición de impactos socioculturales y medioambientales. Tampoco emplea datos de interés relativos a otras ciencias vinculadas a la economía (demografía, extensión del territorio, etc.). También cabe destacar el hecho de no tener en cuenta, si se sigue estrictamente la metodología de la OMT (Naciones Unidas, 2010b), los impactos indirectos que produce el turismo en el consumo y el empleo. Un último factor de error lo conforman los desfases en la recopilación de información por parte de los distintos países (método de recogida de los datos, año en el que se recaba la información, institución encargada...) y el tratamiento de los datos únicamente a nivel nacional, sin profundizar en las regiones o áreas dónde se centra la actividad en el país.

\section{REFERENCIAS BIBLIOGRÁFICAS}

Eurostat (2002). European Implementation Manual on Tourism Satellite Accounts (TSA). Luxemburgo: Publications Office of the European Union.

Eurostat (2009). Tourism Satellite Accounts in the European Union. Volume 3: Practical Guide for the Compilation of a TSA: Directory of Good Practices. Luxemburgo: Office for Official Publications of the European Communities.

Eurostat (2013). Tourism Satellite Accounts (TSAs) in Europe. Luxemburgo: Publications Office of the European Union.

Frechtling, D. (1999). The tourism satellite account: foundations, progress and issues. Tourism Management, 20 (1), 163-170. 
Frechtling, D. (2010). The Tourism Satellite Account A primer. Annals of Tourism Research, 37 (1), 136-153.

Frechtling, D. C. (2013). The Economic Impact of Tourism: Overview and Examples of Macroeconomic Analysis. Madrid: World Tourism Organization.

Hernández Martín, R. (2006). La Cuenta Satélite del Turismo. Metodología y principales resultados en España. En Parra, E. y Calero, F.: Gestión y dirección de empresas turísticas. Madrid: McGraw-Hill.

Hernández Martín, R. (2011): La Cuenta Satélite del Turismo de Canarias. Metodología, resultados y reflexiones. En Y. Armas Cruz (coord.), El turismo en Canarias (pp. 67-91). Santa Cruz de Tenerife: Fundación FYDE-CajaCanarias.

Jones, C. y Munday, M. (2010). Tourism Satellite Accounts for regions? A review of development issues and an alternative. Economic Systems Research, 22 (4), 341-358.

Naciones Unidas (2001). Tourism Satellite Account: Recommended Methodological Framework. Nueva York: Departamento de Asuntos Económicos y Sociales.

Naciones Unidas (2010a). International Recommendations for Tourism Statistics 2008. Nueva York: United Nations Publications.

Naciones Unidas (2010b). Tourism Satellite Account: Recommended Methodological Framework, 2008. Nueva York: Departamento de Asuntos Económicos y Sociales.

Organización Mundial del Turismo (2010). Positioning Tourism in Economic Policy: Evidence and Some Proposals. Madrid: World Tourism Organization.

Organización Mundial del Turismo (2012). Exploring the Full Economic Impact of Tourism for Policy Making. Madrid: United Nations Publications. 